\title{
Study on the Development Strategy for the New Generation of Information Technology Industry during the 13th Five-Year Plan Period
}

\author{
Liang Zhihao, Xu Shouren
}

China Academy of Electronics and Information Technology, Beijing 100041, China

\begin{abstract}
This paper analyzes and sorts out the new generation of information technology sector as a strategic emerging industry during the 12th Five-Year Plan period. This study also extrapolates the general direction of the industry in terms of technological shifts and industry practices during the 13th Five-Year Plan period. Development ideas and constructive opinions for this area are put forward as references for the development of the new generation of information industry during the 13th Five-Year Plan period.
\end{abstract}

Key words: 13th Five-Year Plan; new generation of information technology; strategic emerging industries

\section{Introduction}

The information technology (IT) revolution began in the mid20th century. Innovations in technology have helped IT industry develop rapidly, while penetrating into the products and services of other areas by means of incremental effects, multiplier effects, and technological spillover effects. However, these effects cannot compete with those ones produced by conventional industries, because these effects have radically changed both production and lifestyles in the post-industrial era and have made a profound impact on the development of human society. Information technology industry has become the most important driving force in improving national strength of science and technological innovation, proposing the development of economic society, and enhancing the overall competitiveness. Therefore, grabbing the commanding heights in the field of IT has become a common objective among major powers.

In recent years, the new generation of IT (NGIT) industry represented by the mobile Internet, smart terminals, big data, cloud computing is contributing to advancements in the IT revolution. Based on the general trends in such a technological development, China has emerged into the "new normal" state of a moderate growth rate in economy development. Therefore, according to the predominant industrial characteristics and technical trends, the authors firstly examine the main direction of NGIT during the 13th Five-Year Plan period based on the comprehensive evaluation and analysis of NGIT during the 12th Five-Year Plan period. Furthermore, the authors also propose the development of concepts and opinions related to this field during the 13th Five-Year Plan period with the aim of providing references and assistance to promote industrial development, accelerate the industrial transformation, and upgrade and transform economic development processes.

\section{Strategic emerging industry and NGIT}

\subsection{Presentation and development of the strategic emerging industry}

The strategic emerging industry refers to those industries that are established on the basis of cutting-edge technological breakthroughs, representing new directions for the development

Received date: 21 June 2016; revised date: 28 June 2016

Author information: Liang Zhihao, China Academy of Electronics and Information Technology, engineers. Her current research is strategic management and data mining. E-mail: 7525070@163.com

Funding program: CAE Major Advisory Project "Research on Promotion and Development Planning of China's Strategic Emerging Industry in the 13th Five-Year Plan Period" (No. 2014-ZD-7)

Chinese version: Strategic Study of CAE 2016, 18 (4): 032-037

Cited item: Liang Zhihao, Xu Shouren. Study on the Development Strategy for the New Generation of Information Technology Industry during the 13th Five-Year Plan Period. Strategic Study of CAE, http://10.15302/J-SSCAE-2016.04.005 
of future technologies and industries and reflecting the development trends of the world knowledge-based economy, circular economy, and low-carbon economy. These industries continue to be in the early stages of growth and have immense potential for further development. In addition, they can drive development and play a leading role in today's global economies [1].

Premier Wen Jiabao of the State Council held three symposia on the development of the strategic emerging industry on September 21 and 22, 2009. He proposed that developing the strategic emerging industry is the major strategic choice for China to bridge over difficulties based on the current situation and to focus on the long-term upper level for development. Thus, he also pointed out that the nation should select and develop the strategic emerging industries with an international perspective and strategic thinking, which not only can play an important supporting role for the current economic and social development of China, but also can lead the strategic direction for sustainable future economic and social development [2]. In October 2010, the state council issued the Decision of the State Council on Accelerating the Fostering and Development of Strategic Emerging Industries. While in July 2012, the Development Plan for National Strategic Emerging Industry during the 12th Five-Year Plan Period was also issued and distributed.

During the 12th Five-Year Plan period, NGIT, new energy, biology, high-end equipment manufacturing, and other key fields of strategic emerging industries have achieved exceptional growth in industrial scale. The value added increased from $4 \%$ of the GDP in 2010 to $8 \%$ of the GDP in 2015 [3]. The development of the strategic emerging industries relies on the correct selection of strategies and the leading role of innovation. According to the statistics, the research and development strengths of the companies involved in the strategic emerging industries are approximately twice the average. Without input, no output can be obtained. The revenues from the listed companies of strategic emerging industries and the sales revenues from the sectors of major industries are significantly higher than the overall average. Therefore, the strategic emerging industries have become the new power in China's economic growth.

\subsection{Meaning of NGIT}

From a global perspective, IT has become a field with the most transformational technologies, including new technologies, products, services, models, and ideas to refresh the perception of the vast field and the enormous influence of the information industry. Therefore, the meaning and direction of the NGIT industry also change continually with technological innovations, shifting market demands, and industrial developments.

The emerging information technologies represented by the mobile internet, smart terminals, big data, cloud computing, etc. have become the new focus and direction for another major gradual advancement of the IT industry after the international financial crisis in 2008.

The Development Plan for National Strategic Emerging Industry during the 12th Five-Year Plan Period was developed to accelerate the construction of broadband and integrated, safe, and ubiquitous information networks of the next generation. It also pointed out to promote pioneering work in the development of ultrahigh-speed fiber and wireless communication, the Internet of Things, cloud computing, digital virtual technology, advanced semiconductors, new displays, and other newgeneration information technologies [4]. With the advancement of IT in recent years and its penetration into social production and lifestyles, numerous new growth points are emerging. Thus, new content and the direction of NGIT will also be affected by major changes.

\section{Analysis of the development and characteristics of NGIT industry in China}

\subsection{Development situation of NGIT industry in China}

In recent times, China has rapidly developed innovations in hardware, software, content, and services in the field of IT, with predominant convergence, intelligentization, and applicationoriented features; these achievements will become an important force in leading the new wave of technological innovations. In general, the NGIT industry has become powerful and is now the largest global market for IT products. For the industrial scale (Fig. 1), the main business revenue from the electronic information manufacturing industry reached 11.1 trillion yuan in 2015, with a year-on-year growth of $7.6 \%$; while in the software and IT service industry, the revenue from the software business, in particular, was approximately 4.3 trillion yuan, with a yearon-year increase of $16.6 \%$. The revenue from the electronic information industry increased by $74 \%$ and $216 \%$, respectively, during the 12th Five-Year Plan period. The rapid growth of software and IT services reflects the structure optimization of China's electronic information industry with respect to one field. When compared with the rate of national industrial development (Fig. 2), the value added by China's electronic information industry to the designated size increased by $10.5 \%$, which was $4.4 \%$ higher than the industrial average over the same period. The total revenue and total profit increased by $7.6 \%$ and $7.2 \%$, respectively, which were higher than the industrial average for the same period by $6.8 \%$ and $9.5 \%$, respectively, thus accounting for $10.1 \%$ and $8.8 \%$, respectively, of the overall industry. The electronic information industry maintains its leading position in the industrial economy and its supporting role is growing [5].

NGIT creates obvious clusters in terms of regional development and the regional development patterns emerge throughout the country. Since the start of the 12th Five-Year Plan to promote the development of IT, many industrial clusters with their own characteristics have formed. For example, Beijing and Tianjin, 


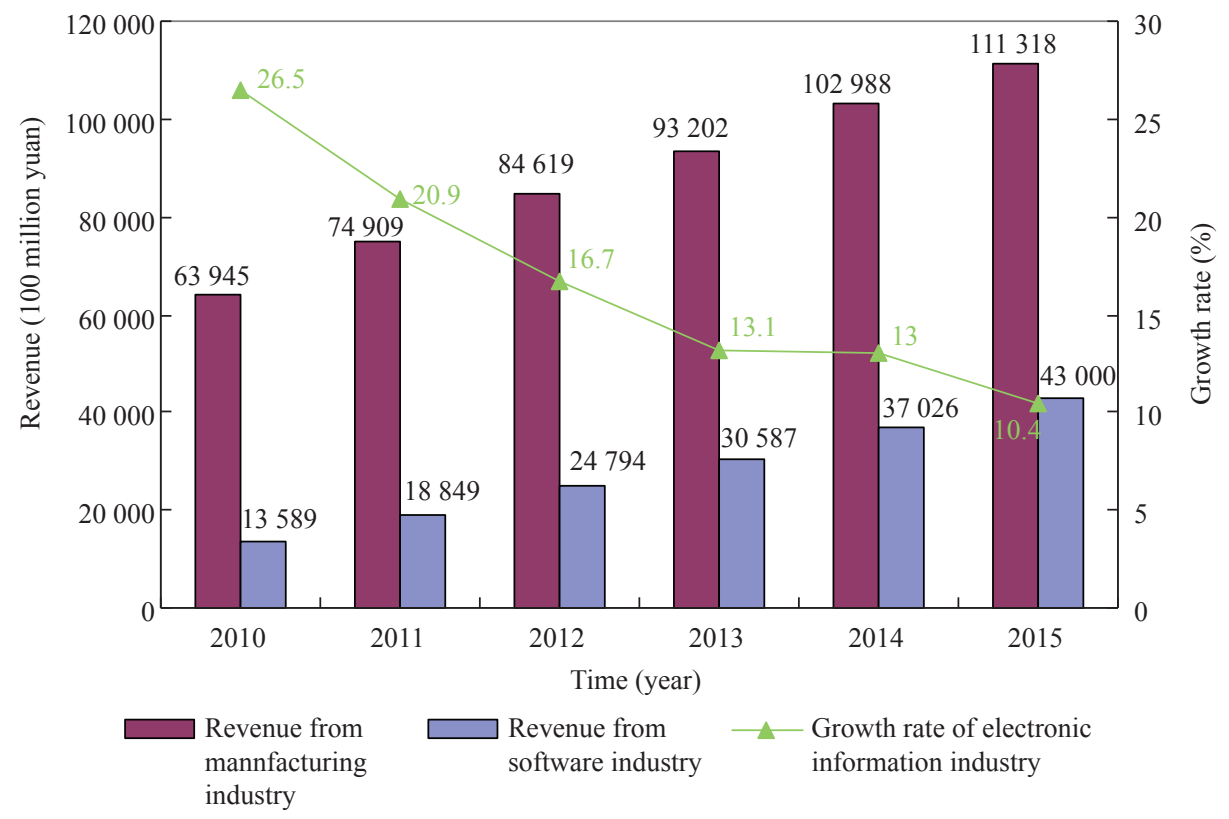

Fig. 1. Growth of the electronic information industry in China from 2010 to 2015 [5].

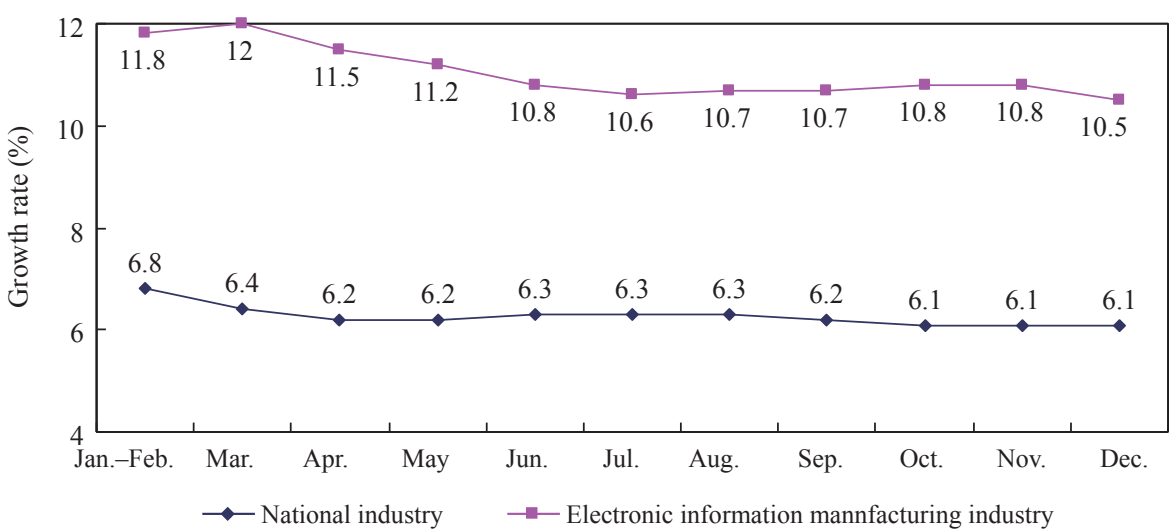

Fig. 2. Comparison between the electronic information industry and national industries in terms of cumulative growth rate of value added [5].

have formed equipment, software platforms, application services, and other industrial clusters of NGIT. Further, the Yangtze River Delta region, which is centered in Shanghai, Hangzhou, and other cities, has formed an industrial cluster area, consisting of a cloud-computing infrastructure and mobile e-commerce. In addition, the Pearl River Delta has formed an industrial cluster with powerful innovations for the Internet of Things. Some central and western regions are actively promoting the structural planning of the IT industry. Chengdu, Chongqing, Xian, and other cities have also formed industrial clusters, such as clusters for IT applications, component manufacturing, and research and development.

\subsection{Development characteristics of the NGIT industry during the 12th Five-Year Plan period}

With the support of national policies, market promotions, and expansion of innovation capacity effects, the NGIT industry has entered a period of rapid growth and fostered many major breakthroughs in the field. These breakthroughs include emerging innovative business models and industrial patterns. Fierce competition exists in core technologies and standards, and industrial chain integration is becoming the key to addressing future competition. In general, the development of the NGIT industry during the 12th Five-Year Plan period can be outlined as follows:

First, the industry continues to achieve rapid growth under the guidance of the government. The Development Plan for National Strategic Emerging Industry during the 12th FiveYear Plan Period defines the multipliers of economic growth, converters of development modes, and boosters of industrial upgrading from the national strategic level for the NGIT industry, and facilitates the developments of the IT industry through several supportive measures. Local governments have issued many preferential policies to support the development of the IT industry in the region. In general, the NGIT industry is developed 
under the leadership of the government. The government and the administrative departments that are responsible for the industry propose planning and deployment by analyzing the development experiences and status for the technology and of the industry at a national and internal level. They define the objectives and directions, guide the flow of capital and talent, and plan the development arrangements suitably.

Second, innovation and integration development have become the latest trend. NGIT is continually creating new business formats and growth points. IT has penetrated into every aspect of traditional industries and has led the industrial restructuring and structural upgrading of both the technical industry and service industry. The innovations and integrations based on the developments of generic technology blur the distinctions between existing industries. Thus, it significantly enhances the inter communication and intersectionality of the industries. Further, the broadening of the value chain and evolution of the entrepreneurial model promote the integrative development of industries. For example, the continuous integration of manufacturing industry and IT promotes the transformation of the manufacturing industry from the productive sector to the service sector. In another example, the new service industry based on IT guides services to develop towards the "informationalized", personalized, and customized direction, and derives multiple types of formats for production and life service.

Third, the competition in the industrial chain has become mainstream. The capacity for industrial chain integration and reconfiguration based on software, services, networks, terminals, and content has become the focus area to seize leadership of the field. From product management to industrial chain management, enterprises can effectively remodel and cultivate the core competitiveness and can leverage the powers and potential in the competition among industries by controlling the key points. The industrial demonstration zone, which is formed based on the industrial chain, reflects the combined industrial effect of NGIT well, while the competitive edge of the industrial cluster transforms from costs to innovations.

\section{Analysis of the experiences and problems of the NGIT industry during the 12th Five-Year Plan period}

\subsection{Experiences of the NGIT industry during the 12th Five- Year Plan period}

China's NGIT maintained rapid growth during the 12th FiveYear Plan period. This is manifested in the expanding industrial scale, significantly improved innovation ability, increasing the number of industrial clusters; further, continuous improvements were achieved at the international level, as well as the growing talent teams. Overall, the role of NGIT in promoting the devel- opment of the national economy and society has increased, and NGIT possesses a strong foundation for the next step. Therefore, the development accomplishments can be summarized as follows:

Strategic deployment is given considerable importance, and strengthen industrial planning and enforcement. China has always attached great importance to the development of the IT industry. Combining with national development objectives and needs, China has developed, planned, and deployed its technology priorities by drawing lessons from the foreign industrial development experience and global development trends. The Decision of the State Council on Accelerating the Fostering and Development of Strategic Emerging Industries issued by the State Council in October 2010 defines NGIT as the national key development orientation and main industry during the 12th Five-Year Plan period. The Twelfth Five-Year Plan for National Economic and Social Development of the People's Republic of China issued in March 2011 further defined the strategic position of the IT industry. Subsequently, China has deployed various strategies in succession, including integrated circuit, promotion of information consumption, mobile internet, smart terminal, big data, Internet plus, and other national strategies.

Promotion mechanisms are coordinated, and the industrial chain is organized for collaborative innovation and integration. China organized the industrial chain for collaborative innovation and integration under leading strategic products. Following the lead of design and manufacturing users, China industry organized mass production and applications of domestic equipment and material products, and promoted the industrialization of the research and development achievements for special equipment, materials, and component products. The Industrial Technology Innovation Alliance was established to strengthen the market demands and to propose the role of the core business by undertaking tasks as the carrier. The effectiveness of these strategies is increased by leveraging the insights of research, improving the research dimensions of the core technologies, and realizing the transformations from technology to products and applications. For example, the experts in China's information security industry creatively presented the concept of cloud security, which is unique in the international cloud computing area. Such technology supersedes the conventional mechanisms of signature scanning for viruses, and is faster for security protection. The complete industrial facilitates the centralization of the competitive edge, and China's NGIT products are gaining worldwide recognition.

Interactive applications and joint action mechanisms of the government, industry, university, and research institutions are combined, and deep integration is strengthened with the enterprises as the main body. The application alliance consisting of the government, industry, university, and research institutions is managed by placing the core enterprises at the center to guide the integration of technical resources and to break 
through bottleneck technique, core technologies, and intellectual property problems. Adhering to the principle of enterprise being the main bodies, China encouraged the enterprise to strengthen this integration by horizontal cooperation and to develop new generations of IT equipment, processes, and products to meet the demands of the industry and markets in laying out special tasks and organizing implementations of projects. Meanwhile, the governments should strengthen the role in supervising and managing the projects, policies, and services. Further, the enterprises, as the participant of forward-looking projects led by universities, should increase their participation in these projects. In addition, the enterprises should directly present their needs, participate in application development, and engage in its appraisal and acceptance of the application to prepare for the preliminary convergence of industrialization of the research and development achievements.

New investment mechanisms are developed, and the environment for industrial investment and financing is improved. China should actively work to facilitate the coordinated development and industrial structural adjustment in the region in organizing and managing the major national tasks of science and technology. Meanwhile, China should also give full play to the combined effects of industrial strength and resource-intensive areas, while enhancing the expansion and leading role of industrial centers across the nation to optimize the industrial structure and improve the environmental conditions. Meanwhile, China should focus on innovation investment mechanisms to promote the development of the strategic emerging industries by guiding diversified investments, improving industrial investments and financing environments, and actively encouraging the large-scale enterprise groups and downstream companies to follow up the investment.

The transfer of scientific and technological achievements is strengthened, and the capacity of industrial independent innovations is promoted. The exploration of scientific and technological achievements transfer mechanism should be intensively strengthened, and especially the transformation of these achievements and the capacities of industry-independent innovations should be improved by technology spillover. In addition, China should strengthen the construction of indigenous intellectual property right, advance the constant improvement and implementation of the protection mechanisms, and the transfer mechanisms of the achievements. To date, it appears that the preliminary results have been achieved, and the protection awareness of intellectual property has been continuously strengthened, thus inspiring the willingness of a company to rely on and persevere in its innovation efforts.

\subsection{Problems identified in NGIT during the 12th Five-Year Plan period}

China's NGIT industry has made remarkable achievements with the support of national policies. However, there is a certain gap in terms of utilizing the international industrial power and potential, driving economic development, and ensuring the security of national defense information. Based on the observations from the past few years, some problems have not yet been solved.

First, the absence of adequate investment and joint forces results in a lack of coordinating mechanisms to cultivate and develop plans. Often, the NGIT industry affects intersecting fields from multiple industries, such as materials, energy, transportation, information, and automation. However, different departments or fields have their own scope with regard to deployment and key supporting points. These departments or fields do not take the entire industrial chain into consideration, thus resulting in relatively decentralized investments. With the rapid development of technology, current investments cannot solve the core problems encountered in the process of industrialization. It becomes difficult to support the NGIT industry in reaching the advanced international level and in meeting market demands. Apart from the investment in research and development, there is scope for improving the fiscal and tax policies, talent policies, import and export policies, financing policies, and other industrial innovation environments required by industrial development.

Second, a generic research and development platform, and a cross-border cooperation mechanism are lacking. Currently, in China, high-end innovative talent engaged in the NGIT industry is limited. Further, the country faces numerous research and development risks and lacks sufficient investment in innovation. The emerging industry of strategic importance requires longer-term cultivation. In the absence of a better environment for technical innovation, many small- and medium-sized enterprises will find it difficult to eliminate the issues of being acquired, restructured, or even eliminated during the course of their development. Sophisticated equipment, advanced testing, and research and development platforms are required to cultivate and develop NGIT. Currently, the domestic enterprises are small in scale and have limited capital investment capacity. It is feasible to strengthen the construction of the platform for generic scientific research according to the present state of the nation's enterprises. We can reduce the repeated purchasing of equipment or leave it unused, while supporting the construction of the industrial environment by integrating existing resources, developing standardized inspections, and developing talent-training and other services.

Third, talent-training strategies are lacking, and serious talent deficiencies and "brain drain" exist. As a knowledge-intensive industry, talent and technology comprise the core competitive edge of NGIT. Owing to the relatively late start in IT education in China, professional talent is significantly inadequate. For example, in the cyberspace security industry, the competition involves more than just technology and products; it includes high-quality security personnel. Today, the cyberspace 
security education and training system in China is not yet complete. We are experiencing a serious shortage of talent. The talent pool is relatively fragmented and unable to form a joint force.

Fourth, intellectual property will be a long-term problem in hindering the development of enterprises in China. Considering the mobile Internet field as an example, the world has created a patent system comprising Apple, Google, and Microsoft. (However, the mobile Internet companies in China are superior in terms of the number of patents held with respect to appearance design for mobile phones, core technologies such as chips, radio frequency chips, etc.) However, these patents are obviously insufficient and cannot form a benefit-sharing mechanism owing to the lack of core technologies for operating systems. A gap exists between the software and hardware enterprises. Commercial enterprises face some inherent legal risks in using open source software.

\section{Overall consideration and policy suggestions for the NGIT industry during the 13th Five-Year Plan Period}

\subsection{Development thoughts}

The strategic focus for the first half of the 13th Five-Year Plan period is to establish a solid technological foundation for the NGIT industry, to develop application markets that coordinate multiple fields and multiple disciplines, and finally to generate mature industrialized technologies for market-oriented major requirements. The strategic focus for the second half of the 13th Five-Year Plan period is to promote the NGIT industry to realize all aspects of the "great-leap-forward" development, to further open markets with innovative applications and enhance the hematopoietic function of enterprises, and in the end to support greater inputs in emerging technology and industry.

Basic principles: The basic principles in cultivating and developing of the NGIT industry are as follows: to give full play to the principal role of enterprises and regional industrial strengths under major demands; to vitalize existing resources by cutting over from the midstream of industries; to promote the roles of science and technology innovation platforms and related service platforms by focusing on the construction of innovative bases; and to adhere to the combination of overall planning and market mechanisms, platform construction and talent training, and domestic- and international-market-oriented policies.

Development objective: The overall objective for the cultivation and development of the NGIT industry during the 13th Five-Year Plan period is to enhance the ability of independent innovation in the IT field, and to support the sustainable development of strategic emerging industries and economies by leveraging historical opportunities for the development of China's NGIT. Further, China must explore ways to demonstrate mechanism innovations, and eliminate bottlenecks and obstacles that restrict technological breakthroughs and industrialized development for strategic emerging industries.

Key directions: In order to promote the upgradeg and transformation of the industrial structure with the inner drive as the core and to realize the transition towards an information industry power in China, NGIT must follow the development trends of the IT industry during its course of "intergenerational change" and "evolution and fission" to realize breakthroughs in key technology and innovations in products from technological research and development, promote model innovations in products and services areas, and promote the construction of complete industrial eco-systems that advance in the value chain. During the 13th Five-Year Plan period, China should focus on the construction of a "three-in-one" information industry ecosystem spanning cloud computing, mobile Internet, and smart terminals and should determine the development priorities from among five aspects, including integrated circuits, smart terminals, wearable devices, mobile Internet, social network services, cloud computing, and cyberspace security.

\subsection{Policy suggestions}

5.2.1. Give full play to the leading role of government and the decisive role of the market

A diversified scientific and technological investment and financing system, which is led by governmental financial investments, considers the cost of scientific research as the main body and supplemented by social capital should be established during the construction of the regional innovation system. Firstly, China should solve the investment issue that cannot be effectively solved by a market resource allocation system in basic and public scientific research. Secondly, it is necessary to carry out the favorable investments according to the needs of industrial development. In addition, different forms of ongoing support should be conducted according to the different links in the industrial chain of the NGIT. The direct governmental investment should prevail in terms of basic scientific research, while in terms of core technological breakthroughs, the enterprises can jointly make relevant studies on common research and development platforms by entrusting development modes. The construction of such platforms is mainly supported by the government, and the enterprises, universities, and research institutes, as well as other organizations, can participate in the construction of the platform by providing funds, equipment, and personnel. In the product development phase, the government should participate in the investment, foster policy guidance, and cultivate the market by direct grants, government procurement, model applications. However, in the industrialization stage, it is prior to construct the standard establishment and common testing platform. Simultaneously, the government should introduce an innovative financial service pattern to establish a NGIT development fund, which can realize the efficient transformation of achievements 
in scientific research and value creation by matching appropriate financial services at different stages of commercialization of research findings.

5.2.2. Create an introduction and training system for creative talent and teams

It is necessary to explore and establish the layered and multiple disciplinary platforms for talent introduction and use to agglomerate and cultivate a cadre of high-end technical talents, as well as talents specializing in transforming the scientific and technological achievements and project management. The introduction of overseas talents, in particular, the young talents and innovative teams, should be strengthened, encouraging overseas experts to innovate and to start a new business. The policies of mixed ownership institutions in talent introduction, settlement, and other aspects should be implemented. In addition, China should establish flexible and diverse ways of creative talent flow and employment, while focusing on cultivating many high-end talents specializing in industrial technology and management, as well as professional and technical engineers. Moreover, China should further implement and deepen the pilots in utilization and disposal of the science and technology achievements, as well as in revenue management and reform, to encourage the institutions of higher learning, scientific research institutes, and stateowned enterprises to improve their proportion of rewarding the scientific and technological personnel in the earnings from the achievement of employee innovation.

5.2.3. Improve the intellectual property system that is conducive to innovation and development of IT

In order to create a favorable institutional environment for technological innovation, China should improve the protection level of intellectual property in accordance with the national conditions, further perfect the laws and regulations, increase the popularity of the legal system of intellectual property, enhance the cultural atmosphere of the intellectual property, and improve the level of intellectual property certification and enforcement Furthermore, China should pay high attention to the key issues in specific areas when exploring the establishment of an intellectual property court to address disputes that may occur in the future.

\section{Reference}

[1] The State Council of the People's Republic of China. The decision of the State Council on accelerating the fostering and development of the strategic emerging industries [EB/OL]. (2010-10-8) [201606-21]. http://www.gov.cn/zwgk/2010-10/18/content_1724848. htm. Chinese.

[2] The State Council Office of the People's Republic of China. Premier Wen Jiabao of the State Council Held 3 Symposia on the development of the strategic emerging industry $[\mathrm{EB} / \mathrm{OL}]$ (2009-09-22) [2016-06-21]. http://www.gov.cn/ldhd/2009-09/22/ content_1423493.htm. Chinese.

[3] Chinese Institute of Engineering Development Strategies. Report on the development of China's strategic emerging industries (2016) [M]. Beijing: Science Press Ltd., 2015. Chinese.

[4] The State Council of the People's Republic of China. Notice of the State Council on issuing the development plan for national strategic emerging industry during the 12th Five-Year Plan period [EB/OL]. (2012-07-20) [2016-06-21]. http://www.gov.cn/ zwgk/2012-07/20/content_2187770.htm. Chinese.

[5] Bureau of Operation Supervision and Coordination of Ministry of Industry and Information Technology of the People's Republic of China. The statistical bulletin for electronic information industry in 2015 [EB/OL]. (2016-02-29) [2016-06-21]. http://www.miit.gov. cn/newweb/n1146285/n1146352/n3054355/n3057511/n3057518/ c4650836/content.html. Chinese. 